\title{
Social media activities during restoration after the Great East Japan Earthquake
}

\author{
H. Koumoto ${ }^{1}$ \& S. Sato ${ }^{2}$ \\ ${ }^{1}$ Graduate School of Environment and Disaster Research, \\ Tokoha University, Japan \\ ${ }_{2}^{2}$ International Research Institute of Disaster Science, \\ Tohoku University, Japan
}

\begin{abstract}
The present study examined social media activities of people in an area affected by disaster during the restoration period. The purposes of the study were to examine whether social media can substitute for the real relationships of communities, and to propose how social media can be utilized to support and restore the lives of disaster victims after a disaster. The study consists of bibliographic research and semi-structured interviews of people who engaged in activities in the area. The use of social media during restoration periods was examined in order to determine if supportive social networks would develop. From the results, both advantages and disadvantages of using social media were clarified in the ongoing restoration. Current situations of the victims separated from their original communities were elucidated.

Keywords: social media, tablet use, restoration, disaster victims, virtual communities, the Great East Japan Earthquake.
\end{abstract}

\section{Introduction}

Social media have been recognized as useful tools utilized during disasters in recent years. They are Internet-based applications such as Facebook, Twitter, Mixi (a Japanese anonymous social networking service). Prompt information sharing and dissemination by social media during disaster response has become widely recognized. However, the use of social media during disaster restoration periods has not been fully studied. 
The Great East Japan Earthquake was the first case in which the support system of private rental housing-turned-into-temporary housing units was extensively adopted, where local governments rent private housing units to provide disaster victims with temporary housing. The number of the disaster victims who applied for this support was larger than the number who applied for prefabricated temporary housing $[1,2]$. Disaster victims who had chosen the designated temporary housing system accordingly live away from communities they had belonged to. This caused concerns that the communities built before the disaster would be disrupted. Under such circumstances, social media have the potential to allow disaster victims to leverage activities and relationships in order to reorganize their lives.

\section{Objectives and method}

The present study, a case study of the Great East Japan Earthquake, examined social media activities of people in the disaster affected area during the restoration period. The purposes were to examine whether social media can substitute for the real relationships of communities, and to propose how social media can be utilized to support and restore the lives of disaster victims by building virtual communities after a disaster.

This study consists of two steps: bibliographic research and semi-structured interviews of people who engaged in disaster recovery activities of Natori city, Miyagi prefecture, Japan. In our first step, media reviews were examined where municipalities had worked towards supporting information sharing between victims and municipalities. In the second step, using semi-structured interviews of disaster victims, the activities they engaged in using social media were examined.

\section{Review of the literature}

After the Great East Japan Earthquake, several studies regarding social media usage in the disaster area were conducted in Japan. Sekiya [3] noted that people had engaged in excessive information dissemination and sharing, and rumour pervaded through Twitter and chain mails during the aftermath. Sekiya [4] also indicated that social media mainly facilitated information sharing in the response period among people outside the affected area, rather than among disaster victims.

Regarding reliability of information obtained from social media in disasters, Sutton [5] indicated that information gathered online using Facebook was fast and accurate at a local level after the Virginia Tech shooting. Despite some concerns about possibilities of sharing misinformation, it seems that social media provide quick and reliable information, if shared under conditions which require participants to use their real names.

As for activities in social media, Liu et al. [6] examined the use of social media in the affected communities in disasters, focusing on online photo sharing. 
Analysing eyewitness photos, they identified several types of shared content such as hazard images, images of post-impact responses, mashup images, etc.

It is assumed that photo sharing is one of the activities unique in disaster affected areas. It can be also considered that typical media activities in response seemed different in Japan from other countries. In addition, the activities that stemmed from affected areas in restoration have not been fully examined in Japan.

\section{Bibliographic overview}

After the Great East Japan Earthquake, many municipal and prefectural governments had been disseminating information via social media. It was to enable disaster victims to obtain necessary information from various channels.

In this process, media reviews were analysed where social media were facilitated in disaster affected communities. Thirty one cases were collected online from newspaper articles and press releases of private companies during the period of March $11^{\text {th }} 2011$ through December $20^{\text {th }} 2013$, by using 120 combinations of 5 keywords: tablets, disaster affected, support, social networking services, and social media.

Those cases were categorized into 14 different purposes of media implementation (Figure 1): enhancing communication, making movies, medical services, study support, watching over the elderly, shopping support, agricultural support, call for volunteers, sightseeing support, building damage survey, browsing magazines, relief supply information, information dissemination, and others. The purpose of enhancing communication was the largest $25.8 \%$, followed by the categories of creating movies $12.9 \%$. Medical services, study support, and watching over the elderly were $9.7 \%$. Shopping support was $6.5 \%$. The other groups were all $3.2 \%$.

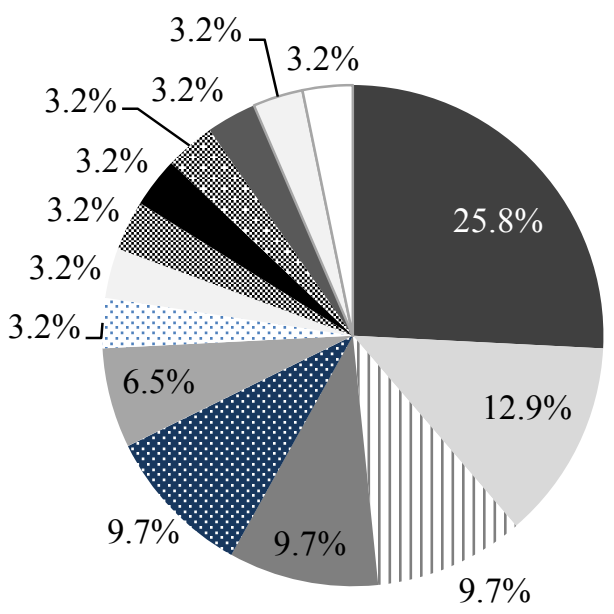

- enhancing communication
making movies
| I medical services
a study support
\$ watching over the elderly
shopping support
$\because$ agricultural support
call for volunteers
$\approx$ sightseeing support
- building damage survey
$\approx$ browsing magazines
$\square$ relief supply information
$\square$ information dissemination
$\square$ others

Figure 1: Purposes of implementing social media. 
Examining the contents, negative evaluations or problems were seen in the groups of communication and shopping support (Figure 2). The other groups were positively rated, although the degree of positive rating of the groups varied. In the group of enhancing communication, the characteristics of the positively evaluated case were that tablets were distributed to those who applied for the service, and lectures on their use were given by local government. Indicated problems were related to the difficulty of use by the elderly. Some of the elderly also felt that they could not feel close relationships through the use of tablets.

In one of the negatively evaluated cases for enhancing communication, for instance, the town hall had distributed one tablet to each family unit. It was revealed, however, that many of the tablets remained unused after distribution. Approximately $60 \%$ were turned on at least once in December, 2012, while $35 \%$ were never used. Daily use remained $35 \%$ or less [7]. It was assumed that one of the reasons for this was that the elderly were not familiar with the tools. In order to improve the situation, lecture sessions were then held on tablet use, encouraging their utilization [8].

One of the main purposes of the implementation of social media was to push information out from a local government toward its disaster victims. It is what Sutton [9] showed her concern about. "[T]he beauty of social media is that there's a lot of information flowing between people because it's a decentralized network" [9], instead of pushing out information. This information flow had not been fully experienced there.

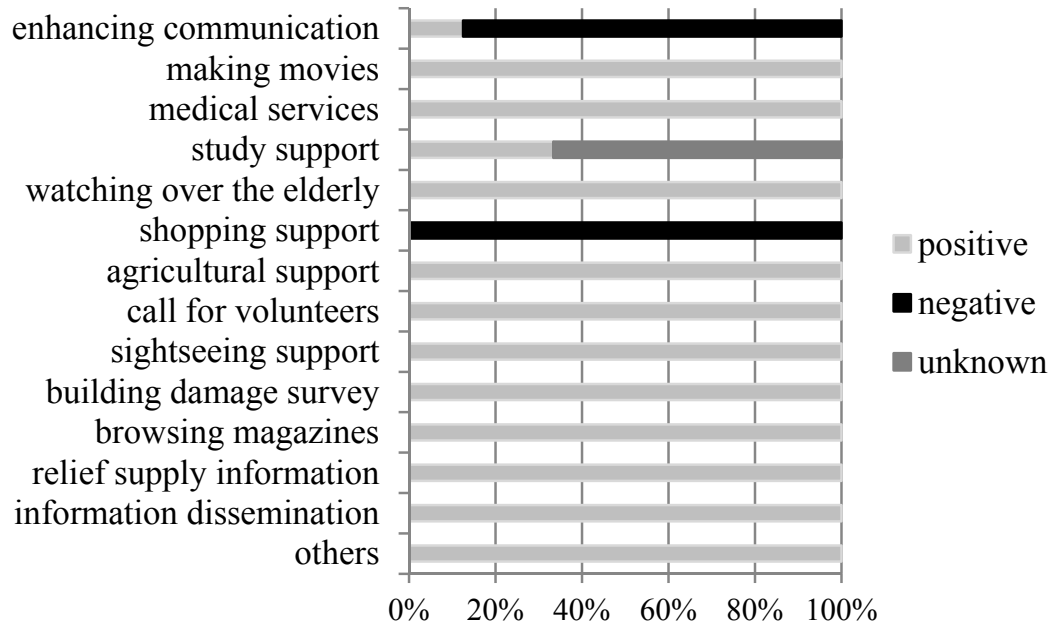

Figure 2: Evaluations of implementations.

According to the Ministry of Internal Affairs and Communications, Japan [10], the largest users of social media are young adults. Approximately $66 \%$ of young people, especially between the ages of 20 through 29 , use social media. The next largest users are those between the ages of 30 and $39,58.9 \%$ of the generation. Less than $20.0 \%$ of elderly people, over the age of 65 , use social 
media. Looking at reasons for using social media, it is shown that the main reason was to communicate with acquaintances, for instance, $88.0 \%$ between the ages of 30 and $39,82.1 \%$ between 40 and $49,72.8 \%$ between 50 and 59 . The second largest reason of using social media was to obtain information, a range of 40 to $50 \%$ in each generation. According to this data, people below the age of 65 spontaneously communicate with others without any support if necessary.

It was also shown in the 2011 survey [11] that more than half of the users $(58.0 \%)$ of tablets had used the service of video-posting and sharing sites. A similar tendency was also seen in smartphone users. Videos appear to draw attention of social media users.

In distributing tablets to a local community, it is essential to support the elderly in their use of the devices and sufficiently explain what they are able to gain by using social media. Compared with the elderly and the aged, younger people are familiar with social media and capable of achieving their purposes with the tool. Combined with videos, information dispatched online potentially draws users' attention.

\section{Interviews of disaster affected people}

In the present study, using retrospective and semi-structured interviews of people who engaged in some activities related to restoration of Natori city after the Great East Japan Earthquake, the activities of social media in the affected area were examined.

Fifteen people, 10 male and 5 female, both disaster victims and non-victims, were interviewed. All of them either live or lived in the city. Three quarters of them had lived in the most devastated area in the city called Yuriage. Candidates of the interviews were introduced through a key person from the city who had already built a trusting relationship with the researchers. They were accessed mainly via Facebook, and those who agreed to cooperate were interviewed. The interviews were conducted from March 2013 to April 2014 (Table 1). They ranged from 30 to 150 minutes, and were recorded.

Interviewees in this study from Yuriage were all victims of the disaster, aged 32 through 56 years. All the interviewees started using social media because of the disaster.

The main purposes of using social media can be categorized into 3 groups: information gathering, information dissemination, information sharing (Table 2). In information gathering, various kinds of information regarding restoration were obtained. Six interviewees from Yuriage utilized social media for information gathering. None of the non-victim interviewees from other areas considered their main purpose as information gathering. In information dissemination, many of the interviewees posted newspaper articles, press-releases from local government, and information about progress of restoration in other affected cities. Some of them posted event information about activities which they were in charge of. It was one of the main purposes of interviewees who were not from Yuriage. 


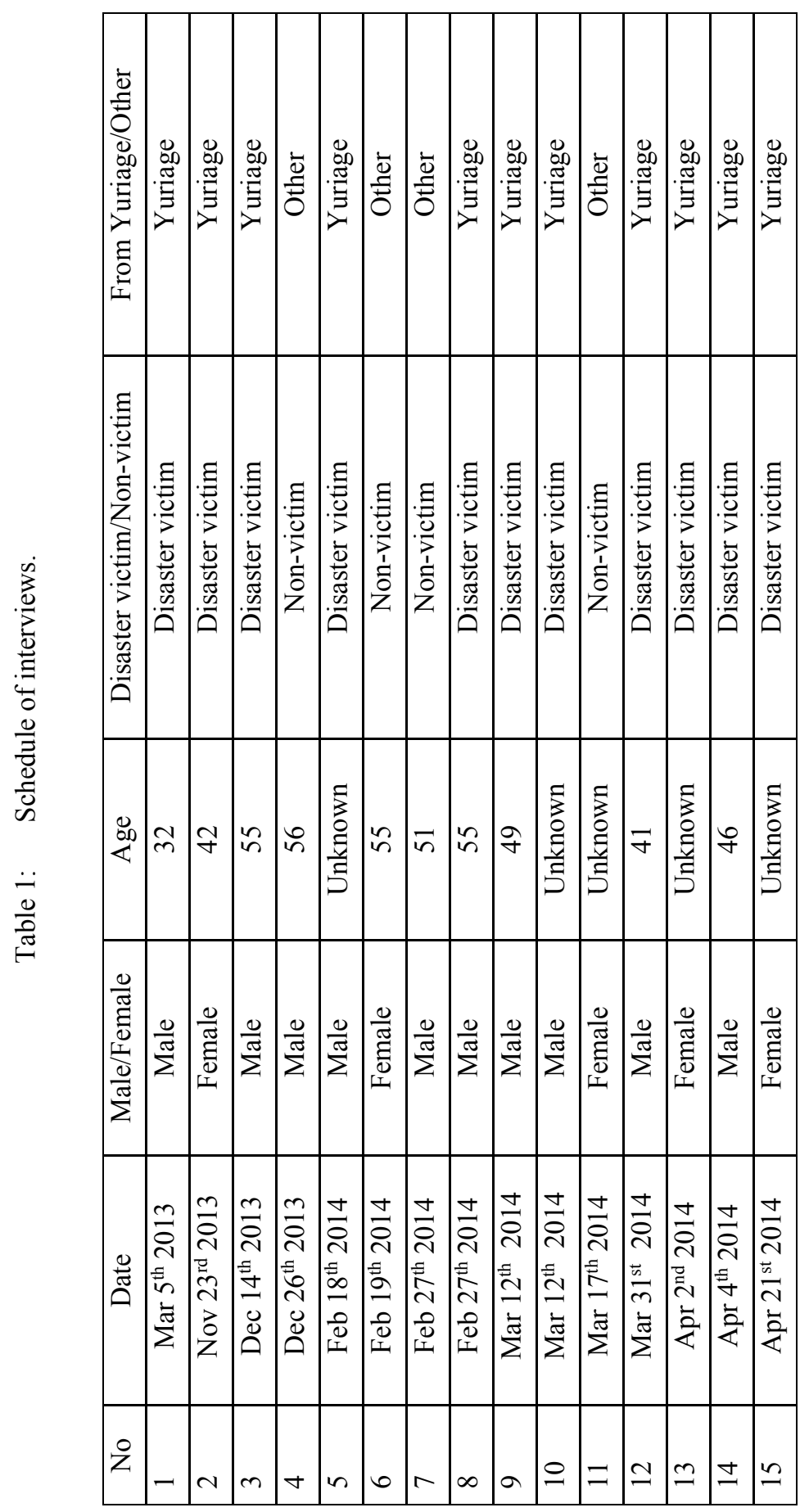


Table 2: $\quad$ Purposes of social media usage by numbers of interviewees.

(Multiple count)

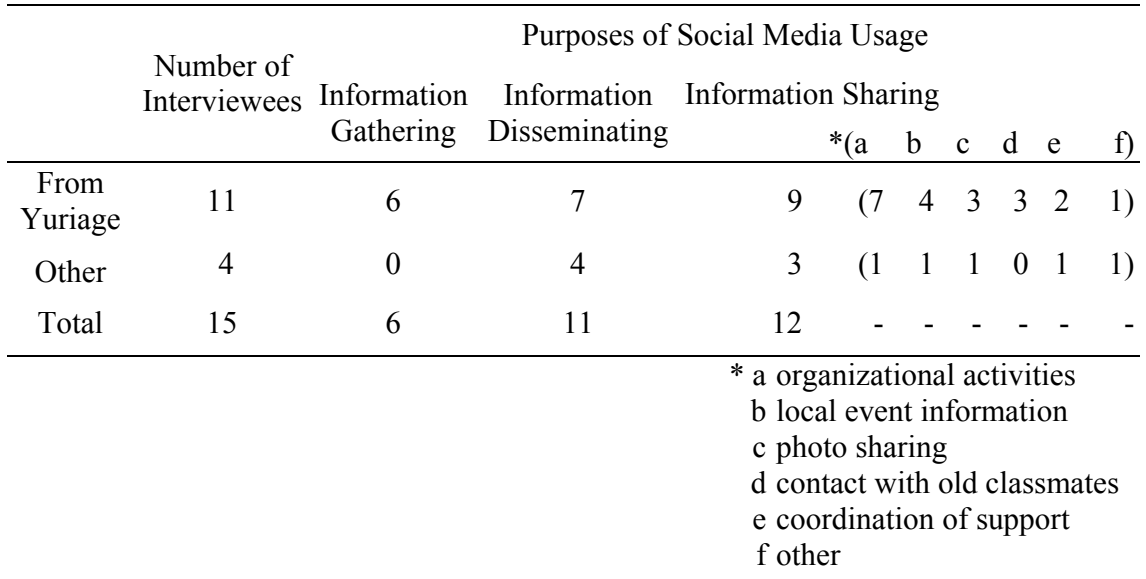

The most popular usage was information sharing. This included private sharing such as exchanging messages. Twelve of them in total, 9 from Yuriage and 3 from other areas, were using Facebook in order to share information. It was apparent that those who disseminated information tended to similarly use the tool to share information.

In information sharing, the top usage was to communicate with group members with whom they cooperated in voluntary activities in restoration (Table 2): youth chamber and cooperative associations, etc. Seven out of the 9 interviewees from Yuriage explained the usage was for organizational activities. Sharing information of local events (such as clean-up activities, planting flowers, and festivals), photo sharing, and coordinating visits and support to the affected area were also engaged in. Old photographs of the neighbourhood before the tsunami and memories were shared within the local group. One of the continuous activities was to share daily events of old classmates in distant cities.

The Japan National Institute of Population and Social Security Research [12] defined the term "community" in Japan as a group composed of citizens with self-initiative and responsibility, having regional characteristics, shared goals, and feelings of trust. The term has recently included invisible networks among social systems due to the development of the Internet [13]. Most information sharing, excluding the sharing of information between old classmates, was to achieve participants' shared aims in restoration activities. It was clarified that some physical neighbourhood communities before the disaster could be partially substituted for by social media networks.

Regarding advantages and disadvantages of using Facebook, it was mentioned that networks of real relationships were strengthened. It was heard 
that some volunteer support groups had returned to visit after being connected online. The tool also enabled them to follow the latest local information without a site visit.

However, disadvantages were also evident. Nine of them mentioned they had recently become tired of using Facebook, and the usage frequency had declined. According to some of the interviewees, the use of Facebook was highest in 2012. There are several possible causes. Information overload made checking all the posted information difficult and frustrating. Posted messages were often conducive to inundation and flaming. Some interviewees experienced possibilities of physical threats to their family members, which was caused by the messages they shared. In the restoration period, people in the disaster affected area often feel anxiety toward their uncertain future due to the slow reconstruction of the local area. Associated with each complicated circumstance, controversial topics online, especially regarding restoration and reconstruction, can be easily misinterpreted by others and become a cause of discontent. For this reason, posted messages tended to be visually appealing and do not express real opinions.

\section{Conclusion}

The present study

1) reaffirmed that bi-directional information sharing in restoration should be included in the main purposes of implementing tablets in order to be actively utilized. It is also essential to promote motivation and selfinitiative of potential users.

2) classified social media usage in disaster affected area by local government into 14 groups: enhancing communication, making movies, medical services, study support, watching over the elderly, shopping support, agricultural support, call for volunteers, sightseeing support, building damage survey, browsing magazines, relief supply information, information dissemination, and others, by using media review information released online.

3) confirms that it is necessary to prepare informative lectures for the elderly during distribution of tablets in disaster affected areas.

4) indicates that social media were utilized in information gathering, disseminating, and sharing in the restoration by the affected people.

5) clarified prominent and spontaneous social media activities in restoration in the disaster affected area: communicating with voluntary group members which they belong to, sharing information of local events, coordinating a visit in the affected area, receiving support from outside, and photo sharing.

6) indicates that the rate of utilization of social media tended to be highest during the second year after the disaster.

7) reconfirms the importance of exchanging opinions offline in controversial decision making in restoration as well as online communication. 


\section{Acknowledgements}

We thank the interviewees who cooperated in the present study. This study was funded by the Research Institute of Science and Technology for Society, Japan Science and Technology Agency, and was one of the research projects in the Research and Development Outcomes Contribute to Society by Addressing Social Challenges-Focus Area: Creating Community-based Robust and Resilient Society. We would like to express our great appreciation for their support. We are grateful to S. Tatsuki, a professor of Doshisha University and the research representative of the project. We also wish to acknowledge the support in English provided by J.B. Laing, an associate professor of Tokoha University. We express our sincere gratitude to everyone who cooperated.

\section{References}

[1] Japan Ministry of Land, Infrastructure, Transport and Tourism, Support of Construction of Temporary Housing Units in the Great East Japan Earthquake. Retrieved on January 5, 2015, from http://www.mlit.go.jp/ common/000170090.pdf

[2] Japan Reconstruction Agency, Transition of the number of temporary housing units by local governments' renting private housing units. Retrieved on January 5, 2015, from http://www.reconstruction.go.jp /topics/0813_minchin.pdf

[3] Sekiya, N., Anxiety and Information Behaviour after the Great East Japan Earthquake. The Journal of Information Science and Technology Association, Vol. 62, No. 9, pp. 372-377, 2012.

[4] Sekiya, N., Problems of Press Report and Media in the Great East Japan Earthquake. Newspaper Research, No. 720, pp.58-63, 2011.

[5] Sutton, J., Public Uses Social Networking During Disasters to Verify Facts, Coordinate Information. Retrieved on January 5, 2015, from http://www.emergencymgmt.com/safety/The-Public-Uses-SocialNetworking.html.

[6] Liu, S., Palen, L., Sutton, J., Hughes, A., and Vieweg, S., In Search of the Bigger Picture: The Emergent Role of On-Line Photo Sharing in Times of Disaster, Proceedings of the $5^{\text {th }}$ International ISCRAM Conference, Washington, DC, USA, 2008.

[7] Kahoku Shimpo Publishing Co., Tablets Distributed to Evacuees, Elderly Avoid in Iidate-mura, January 20, 2013.

[8] Nikkei Asian Review, Tablets in Restoration/Docomo Broadens Aid Network, Technology, March 10, 2013.

[9] Sutton, J., Social Media Brings Together Resources, Creates More Resilient Communities (Analysis, Social Media Package Part 2 of 2). Retrieved on January 5, 2015, from http://www.emergencymgmt.com /safety/Social-Media-Brings-Together-Resources.html.

[10] Japan Ministry of Internal Affairs and Communications, Results of Communications Usage Trend Survey 2013. Retrieved on January 6, 2015, 
from http://www.soumu.go.jp/johotsusintokei/statistics/statistics05a/h25 doukou.html

[11] Japan Ministry of Internal Affairs and Communications, Results of Communications Usage Trend Survey 2011. Retrieved on January 6, 2015, from http://www.soumu.go.jp/johotsusintokei/statistics/data/120530_1.pdf

[12] Japan National Institute of Population and Social Security Research, Community: Recovery of Humanity in a Place to Live. Retrieved on January 9, 2015, from http://www.ipss.go.jp/publication/j/shiryou/no.13/ data/shiryou/syakaifukushi/32.pdf

[13] Iida, K., Definition of Community in Community Psychology and Individuality of Community Psychology. Ritsumeikan Social Science Annals, vol. 49, No. 4, pp. 79-99, 2014, 